\title{
Centralization of Esophageal Cancer Surgery: Does It Improve Clinical Outcome?
}

\author{
M. W. J. M. Wouters, $\mathrm{MD}^{1,7}$, H. E. Karim-Kos, $\mathrm{PhD}^{2}$, S. le Cessie, $\mathrm{PhD}^{2,3}$, B. P. L. Wijnhoven, MD, $\mathrm{PhD}^{4}$, \\ L. P. S. Stassen, MD, $\mathrm{PhD}^{5}$, W. H. Steup, $\mathrm{MD}, \mathrm{PhD}^{6}$, H. W. Tilanus, $\mathrm{MD}, \mathrm{PhD}^{4}$, and R. A. E. M. Tollenaar, $\mathrm{MD}$, \\ $\mathrm{PhD}^{1}$
}

${ }^{1}$ Department of Surgery, Leiden University Medical Center, Leiden, The Netherlands; ${ }^{2}$ Comprehensive Cancer Center West, Leiden, The Netherlands; ${ }^{3}$ Department of Medical Statistics, Leiden University Medical Center, Leiden, The Netherlands; ${ }^{4}$ Department of Surgery, Erasmus University Medical Center, Rotterdam, The Netherlands; ${ }^{5}$ Department of Surgery, Reinier de Graaf Hospital, Delft, The Netherlands; ${ }^{6}$ Department of Surgery, HAGA Hospital, The Hague, The Netherlands; ${ }^{7}$ Department of Surgical Oncology, Netherlands Cancer Institute, Antoni van Leeuwenhoek Hospital, Amsterdam, The Netherlands

\begin{abstract}
Background. The volume-outcome relationship for complex surgical procedures has been extensively studied. Most studies are based on administrative data and use inhospital mortality as the sole outcome measure. It is still unknown if concentration of these procedures leads to improvement of clinical outcome. The aim of our study was to audit the process and effect of centralizing oesophageal resections for cancer by using detailed clinical data.
\end{abstract}

Methods. From January 1990 until December 2004, 555 esophagectomies for cancer were performed in 11 hospitals in the region of the Comprehensive Cancer Center West $(\mathrm{CCCW}) ; 342$ patients were operated on before and 213 patients after the introduction of a centralization project. In this project patients were referred to the hospitals which showed superior outcomes in a regional audit. In this audit patient, tumor, and operative details as well as clinical outcome were compared between hospitals. The outcome of both cohorts, patients operated on before and after the start of the project, were evaluated.

Results. Despite the more severe comorbidity of the patient group, outcome improved after centralizing esophageal resections. Along with a reduction in

(C) The Author(s) 2009. This article is published with open access at Springerlink.com

First Received: 13 December 2007;

Published Online: 16 April 2009

M. W. J. M. Wouters, MD

e-mail: m.w.j.m.wouters@lumc.nl postoperative morbidity and length of stay, mortality fell from $12 \%$ to $4 \%$ and survival improved significantly $(P=$ $0.001)$. The hospitals with the highest procedural volume showed the biggest improvement in outcome.

Conclusion. Volume is an important determinant of quality of care in esophageal cancer surgery. Referral of patients with esophageal cancer to surgical units with adequate experience and superior outcomes (outcomebased referral) improves quality of care.

The number of publications that report on the relationship between the volume of high-risk surgical procedures and patient outcome continues to grow. ${ }^{1}$ Most studies show better outcome with increasing number of operations performed by a specialized center or surgeon. However, there is still a debate about the level of evidence of these studies and the appropriateness of minimum volume thresholds for high-risk surgical procedures. ${ }^{2-4}$ For example, there are no randomized controlled trials that have compared outcome for complex surgical procedures between high- and lowvolume hospitals. Despite this apparent lack of evidence, authors claim that many surgical deaths could be saved by centralizing these high-risk procedures. ${ }^{5}$ However, studies that have analyzed the actual effect of centralization (or regionalization) on hospital volumes and outcomes are rare. ${ }^{6}$

It has been widely acknowledged that esophagectomy for cancer is a complex surgical procedure and that concentration in high-volume centers could lead to improved outcome. ${ }^{7,8}$ However, translation of the conclusions of observational series to clinical practice is difficult. Cutoff 
values between high- and low-volume esophageal surgery vary greatly between studies. In The Netherlands, van Lanschot et al. investigated the volume-mortality relationship for esophageal resections, analyzing data from the Dutch National Medical Registry. ${ }^{9}$ The results of their study where in favour of patients treated in the high volume hospitals in our country, suggesting that referring patients to hospitals with higher case-volumes could reduce postoperative mortality. The purpose of our study was to analyze whether centralization of esophageal cancer surgery truly improves clinical outcome. Besides mortality, we were also interested in a more extensive set of outcome measures, including overall survival. As case mix has also been shown to be an important predictor for treatment outcomes, we included detailed clinical data of individual patient and tumor characteristics. ${ }^{10}$

\section{PATIENTS AND METHODS}

\section{Comprehensive Cancer Center Leiden}

Eleven hospitals in the mid-western part of The Netherlands are affiliated to the Comprehensive Cancer Center West $(\mathrm{CCCW})$. In this urbanized area travelling distances between hospitals are not more than $45 \mathrm{~km}$ (30 miles). In 1997, a Professional Network of Surgical Oncologists (PNSO) involving all affiliated hospitals was established, with the objective of improving the effectiveness and efficiency of surgical care for patients with cancer. In the light of the increasing number of reports on a volume-outcome relationship for esophagectomies, the network decided to evaluate surgical care for patients with esophageal cancer treated in the CCCW region since the year 1990.

\section{Retrospective Registration}

All surgically treated esophageal carcinomas from 1990 to 1999 were identified through the cancer registry of the $\mathrm{CCCW}$, in which all cancer patients diagnosed and treated in the mid-western part of The Netherlands ( 1.7 million inhabitants) are registered. All 11 hospitals formally gave their consent to participate in this audit and were subsequently visited by two investigators who retrieved the original patient files. Patient demographics, pathological notes, data on surgical and (neo)adjuvant treatments, comorbidity as well as postoperative morbidity, mortality, length of stay, and survival were extracted from the patients' files. Pathological notes were reviewed in detail by two independent researchers and all cancers were staged according to the tumor-node-metastasis (TNM) staging system of the International Union against Cancer (UICC) 1997. The obtained pTNM stages were then cross-checked with the tumor stages in the cancer registry. Discrepancies in tumor stage were discussed between the researchers and a trained data manager from the $\mathrm{CCCW} /$ cancer registry database. If consensus could not be reached, the tumor stage was classified as "unknown."

\section{Intervention}

In January 2000 the results of this retrospective analysis were presented at the PNSO meeting. ${ }^{10}$ Differences in volume and outcome between hospitals were discussed and all surgeons agreed to participate in a prospective registration. Also, all surgeons agreed upon the scenario of having to refer esophageal cancer patients to centers with a better outcome if their own results proved to be unfavorable (outcome-based referral). These referrals were on a voluntary basis, however, for both the patient and surgeon.

\section{Prospective Registration}

From January 2000 until December 2004 the same data were prospectively collected from the original patient files, and again all affiliated hospitals took part in this exercise. Completeness of the data was cross-checked with the independently collected information from the cancer registry. Each year, interim results were presented and discussed within the group of surgeons at the meeting of the PNSO.

\section{Control Group}

To put the data of the CCCW in national perspective, we compared the outcome of the $\mathrm{CCCW}$ region with the results of the nearest referral center for esophagectomy outside the CCCW region. In this high-volume university hospital, information of patients operated on for an esophageal carcinoma is prospectively collected from original patient files by a data manager.

\section{Statistics}

Differences in patient, tumor, and treatment characteristics, as well as in outcome measurements were assessed using the Kruskal-Wallis test for continuous variables and the chi-square test for categorical variables. Patients with an "unknown" status for a given variable were excluded for the analyses. Duration of survival was calculated as the difference between date of surgery and either date of death or date of last patient contact. To prevent the problem of differential follow-up, for all groups follow-up was cut-off at 2 years after surgery. Observed survival rates were estimated by using the Kaplan-Meier method. The logrank test was used to assess differences in survival between patients who were operated in different time periods and in 
low- versus high-volume hospitals. The Cox proportional hazard model was used to calculate hazard ratios, adjusting for possible confounding variables. All analyses were conducted using SPSS software (version 12.0; SPSS Inc., Chicago, IL).

\section{RESULTS}

\section{Hospital Volume}

Between 1990 and 2004, evaluation and treatment of patients with esophageal cancer was performed in 11 hospitals in the region of the CCCW (one university hospital, five teaching hospitals, and five general hospitals). In 555 consecutive patients, an esophageal tumor was resected with curative intent. Figure 1a illustrates the distribution of surgical procedures within the studied time period for the 11 hospitals, and Fig. 1b shows the resection rates for
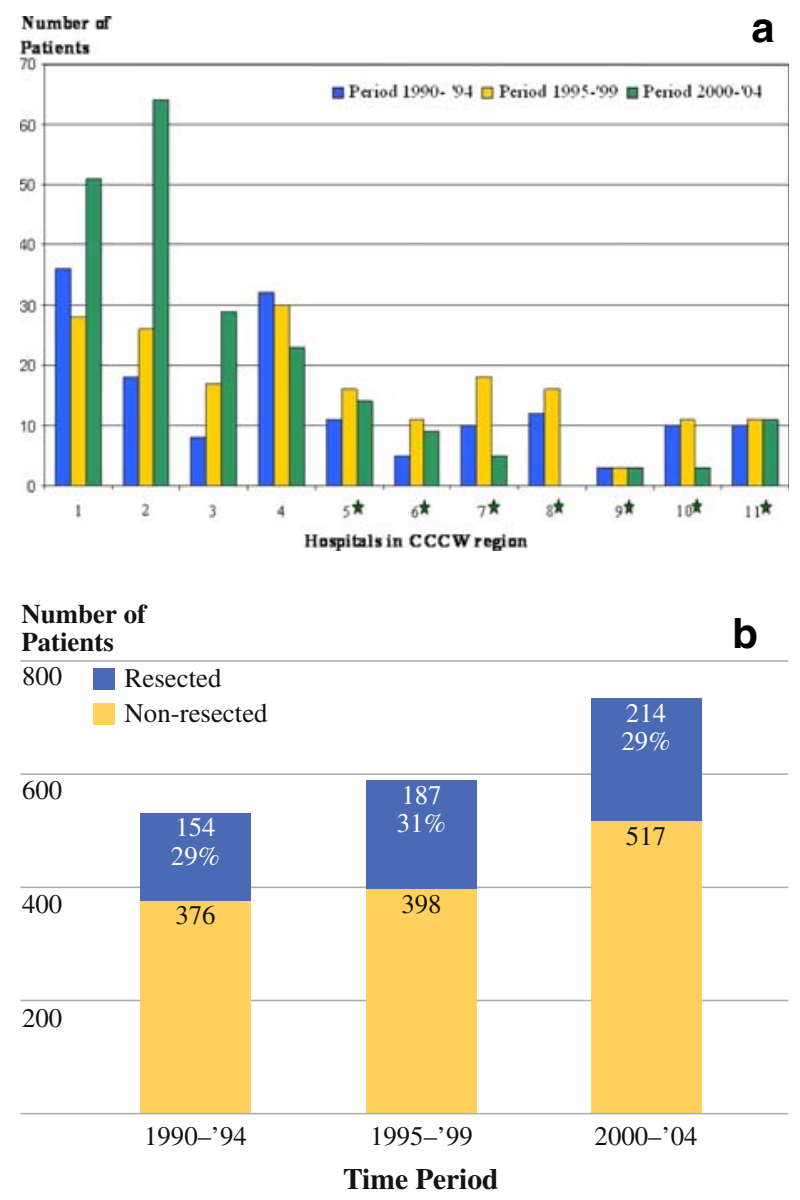

FIG. 1 a Number of esophageal resections in hospitals in region of CCCW per 5-year period (1990-1994, 1995-1999, 2000-2004). *Hospitals that abandoned esophageal resections during 2000-2004 period. Hospital 4 abandoned esophageal resections after 1st January 2005. b Resection rates of newly diagnosed patients with esophagus carcinoma in hospitals in CCCW region per 5-year period (19901994, 1995-1999, 2000-2004) esophageal carcinomas diagnosed in the $\mathrm{CCCW}$ region in three different time periods.

From 1990 to 1999 , none of the hospitals performed more than seven esophageal resections per year (low-volume hospitals; LVH). From the year 2000 onwards, a gradual concentration of esophageal resections occurred, and in two hospitals (I and II) procedural volumes increased to more than ten resections per year (high-volume hospitals; $\mathrm{HVH}$ ). In the same period of time, a mean annual number of 56 esophageal resections was performed in the nearest high-volume center.

\section{Patient, Tumor, and Treatment Characteristics}

Table 1 shows the patient, tumor, and procedural characteristics of esophageal resections performed in three consecutive time periods. There was no significant difference in age, gender, histological type or location of the tumors. However, the number of patients with comorbidities increased during the study period. Stage I tumors were more frequently seen in the later time periods, and an increasing number of transhiatal resections were performed. The number of nodes evaluated by the pathologist changed in time, with a mean number of $6.3,7.5$, and 13.5 nodes reported for the different time periods. In the 2000 2004 time period more neoadjuvant chemotherapy was used, especially in patients with a tumor in the lower esophagus, included in a trial on perioperative epirubicin, cisplatin, and fluorouracil (ECF). ${ }^{11}$

\section{Outcome}

The outcome of esophagectomies in the CCCW region improved with time (Table 2). The percentage of patients with a microscopic radical resection (R0) improved from $69 \%$ to $73 \%$. The number of patients who left the hospital without adverse events was highest in the 2000-2004 period. Hospital stay was shortened significantly and inhospital mortality was reduced almost threefold. As shown in Fig. 2, significantly better 2-year survival is seen for the last time period $(P=0.001)$. After exclusion of in-hospital mortality, this difference is still significant $(P=0.045)$.

Table 3 shows the results of a multivariate analysis for the risk of dying after surgery in the three time periods with adjustments for the impact of the covariates: stage, comorbidity, surgical approach, and neoadjuvant treatments. Somewhat higher stages of the disease and more patients with multiple comorbidities were operated in the last time period. Although there are significant differences in surgical approach and the use of neoadjuvant chemotherapy between time periods, the survival benefit in the 2000-2004 period remains significant in multivariate analysis [hazard ratio (HR) 0.61]. An analysis of the data 
TABLE 1 Characteristics of patients who underwent esophageal resection by period of surgery

$G E$ gastro-esophageal

a "Unknown" category was excluded

b Linear trend analysis

c Squamous versus adenocarcinoma plus Barrett's dysplasia

d Distal esophagus/GE-junction versus others

e No neoadjuvant therapy versus others

f Abdomino-cervical versus others

g Cervical versus thoracic plus abdominal

\begin{tabular}{|c|c|c|c|c|c|c|c|}
\hline \multirow[t]{2}{*}{ Characteristics } & \multicolumn{2}{|c|}{ 1990-1994 } & \multicolumn{2}{|c|}{ 1995-1999 } & \multicolumn{2}{|c|}{ 2000-2004 } & \multirow[t]{2}{*}{$P$ value } \\
\hline & $\begin{array}{l}\text { No. of } \\
\text { patients }\end{array}$ & $\%$ & $\begin{array}{l}\text { No. of } \\
\text { patients }\end{array}$ & $\%$ & $\begin{array}{l}\text { No. of } \\
\text { patients }\end{array}$ & $\%$ & \\
\hline Age (years) & & & & & & & 0.19 \\
\hline Median & 66 & & 65 & & 64 & & \\
\hline Range & $37-87$ & & $33-85$ & & $33-86$ & & \\
\hline Gender & & & & & & & 0.70 \\
\hline Male & 109 & 70.8 & 139 & 74.3 & 159 & 74.3 & \\
\hline Female & 45 & 29.2 & 48 & 25.7 & 55 & 25.7 & \\
\hline Comorbidity & & & & & & & $0.25^{\mathrm{a}, \mathrm{b}}$ \\
\hline No & 68 & 44.2 & 74 & 39.6 & 83 & 38.8 & \\
\hline 1 organ system & 51 & 33.1 & 61 & 32.6 & 85 & 39.7 & \\
\hline 2 organ systems & 19 & 12.3 & 30 & 16.0 & 41 & 19.2 & \\
\hline$\geq 3$ organ systems & 4 & 2.6 & 7 & 3.7 & 4 & 1.9 & \\
\hline Unknown & 12 & 7.8 & 15 & 8.0 & 1 & 0.5 & \\
\hline Histology & & & & & & & $0.93^{\mathrm{a}, \mathrm{c}}$ \\
\hline Adenocarc. & 107 & 69.5 & 130 & 69.5 & 144 & 67.3 & \\
\hline Squamous carc. & 45 & 29.2 & 51 & 27.3 & 52 & 24.5 & \\
\hline Barrett's dysplasia & 1 & 0.6 & 3 & 1.6 & 6 & 2.8 & \\
\hline Others & - & - & 2 & 1.1 & 5 & 2.3 & \\
\hline Unknown & 1 & 0.6 & 1 & 0.5 & 7 & 3.3 & \\
\hline Tumor localization & & & & & & & $0.97^{\mathrm{a}, \mathrm{d}}$ \\
\hline Cervical esoph. & 4 & 2.6 & 3 & 1.6 & 4 & 1.9 & \\
\hline Mid esoph. & 23 & 14.9 & 30 & 16.0 & 32 & 15.0 & \\
\hline Distal esoph./GE junction & 127 & 82.5 & 152 & 81.3 & 177 & 82.7 & \\
\hline Unknown & - & - & 2 & 1.1 & 1 & 0.5 & \\
\hline Stage (pTNM) & & & & & & & $0.65^{\mathrm{a}}$ \\
\hline 0 & 2 & 1.3 & 5 & 2.7 & 6 & 2.8 & \\
\hline I & 10 & 6.5 & 26 & 13.9 & 31 & 14.5 & \\
\hline II & 80 & 51.9 & 80 & 42.8 & 82 & 38.3 & \\
\hline III & 52 & 33.8 & 60 & 32.1 & 74 & 34.6 & \\
\hline IV & 9 & 5.8 & 12 & 6.4 & 15 & 7.0 & \\
\hline Unknown & 1 & 0.6 & 4 & 2.1 & 6 & 2.8 & \\
\hline Neoadjuvant treatment & & & & & & & $<0.001^{\mathrm{a}, \mathrm{e}}$ \\
\hline No & 150 & 97.4 & 165 & 88.2 & 160 & 74.8 & \\
\hline Chemo \pm radiotherapy & 2 & 1.3 & 19 & 10.1 & 54 & 25.2 & \\
\hline Unknown & 2 & 1.3 & 3 & 1.6 & - & - & \\
\hline Surgical approach & & & & & & & $<0.001^{\mathrm{a}, \mathrm{f}}$ \\
\hline Abdomino-cervical & 53 & 34.4 & 97 & 51.9 & 156 & 72.9 & \\
\hline Thoraco-abdominal & 62 & 40.3 & 34 & 18.2 & 11 & 5.9 & \\
\hline Abd-thor-cervical & 16 & 10.4 & 27 & 14.4 & 27 & 12.6 & \\
\hline Abdominal & 23 & 14.9 & 29 & 15.5 & 15 & 7.0 & \\
\hline Unknown & - & - & - & - & 5 & 2.3 & \\
\hline Anastomoses & & & & & & & $<0.001^{\mathrm{g}}$ \\
\hline Cervical & 69 & 44.8 & 126 & 67.4 & 187 & 87.4 & \\
\hline Thoracic & 60 & 39.0 & 30 & 16.0 & 12 & 5.6 & \\
\hline Abdominal & 25 & 16.2 & 31 & 16.6 & 15 & 7.0 & \\
\hline Total no. of patients & 154 & & 187 & & 214 & & \\
\hline
\end{tabular}


TABLE 2 Outcome after esophageal resections in region of CCCW (1990-1994, 19951999, 2000-2004) a "Unknown" category excluded

b Patients who died during hospital stay were not included

c R0 versus R1 plus R2

${ }^{\mathrm{d}}$ No reintervention versus others

\begin{tabular}{|c|c|c|c|c|c|c|c|}
\hline \multirow[t]{2}{*}{ Outcome } & \multicolumn{2}{|l|}{ 1990-1994 } & \multicolumn{2}{|l|}{ 1995-1999 } & \multicolumn{2}{|l|}{ 2000-2004 } & \multirow[t]{2}{*}{$P$ value } \\
\hline & No. of patients & $\%$ & No. of patients & $\%$ & No. of patients & $\%$ & \\
\hline Margins & & & & & & & $0.57^{\mathrm{a}, \mathrm{c}}$ \\
\hline R0 & 107 & 69.5 & 140 & 74.9 & 156 & 72.9 & \\
\hline R1 & 34 & 22.1 & 21 & 11.2 & 39 & 18.2 & \\
\hline $\mathrm{R} 2$ & 10 & 6.5 & 25 & 13.4 & 12 & 5.6 & \\
\hline Unknown & 3 & 1.9 & 1 & 0.5 & 7 & 3.3 & \\
\hline Complications & & & & & & & $0.20^{\mathrm{a}}$ \\
\hline No & 43 & 27.9 & 46 & 24.6 & 70 & 32.7 & \\
\hline Yes & 106 & 68.8 & 140 & 74.9 & 143 & 66.8 & \\
\hline Unknown & 5 & 3.2 & 1 & 0.5 & 1 & 0.5 & \\
\hline Reintervention & & & & & & & $0.27^{\mathrm{a}, \mathrm{d}}$ \\
\hline None & 115 & 74.4 & 155 & 82.9 & 163 & 76.2 & \\
\hline 1 & 27 & 17.5 & 21 & 11.2 & 32 & 15.0 & \\
\hline 2 & 5 & 3.2 & 7 & 3.7 & 12 & 5.6 & \\
\hline$\geq 3$ & 2 & 1.3 & 3 & 1.6 & 3 & 1.4 & \\
\hline Unknown & 5 & 3.2 & 1 & 0.5 & 4 & 1.9 & \\
\hline Hospital stay (days) ${ }^{\mathrm{b}}$ & & & & & & & 0.002 \\
\hline Median & 20 & & 21 & & 17 & & \\
\hline Range & $(9-92)$ & & $(9-125)$ & & $(8-273)$ & & \\
\hline In-hospital mortality & & & & & & & $0.003^{\mathrm{a}}$ \\
\hline No & 131 & 85.1 & 160 & 85.6 & 204 & 95.3 & \\
\hline Yes & 22 & 14.3 & 23 & 12.3 & 10 & 4.7 & \\
\hline Unknown & 1 & 0.6 & 4 & 2.1 & - & - & \\
\hline Total no. of patients & 154 & & 187 & & 214 & & \\
\hline
\end{tabular}

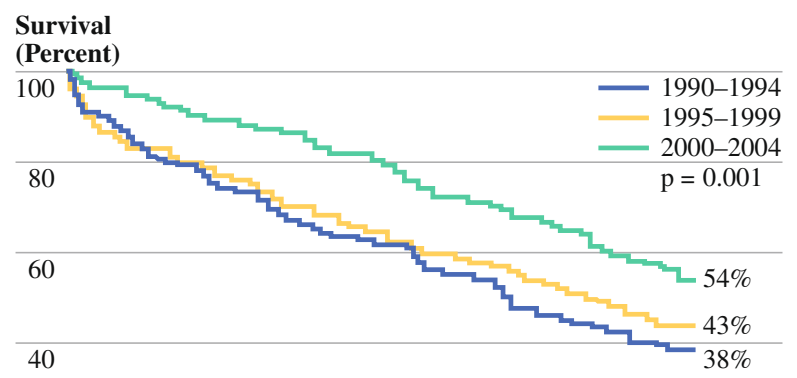

20

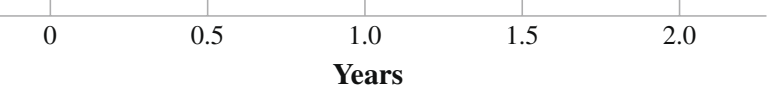

FIG. 2 Two-year survival after resection for all stages of esophageal carcinoma in three time periods (p1: 1990-1994, p2: 1995-1999, p3: 2000-2004), including hospital mortality

after exclusion of patients who received (neo)adjuvant treatment showed similar improvements in mortality rates and survival after 2000. Also, a multivariate analysis was performed after exclusion of the patients who died during hospital stay (Table 4). Improvements in survival stayed (borderline) significant after adjustments for differences in stage, age, gender, and comorbidities $(P=0.05)$, but after introducing surgical approach in the model, significance was lost $(P=0.25)$.

In Table 5 patient, tumor, and treatment characteristics of patients operated on in hospitals with fewer than ten resections a year (low-volume hospitals LVH) and with more than nine resections a year (high-volume hospitals HVH) are shown. Only patients operated in a year in which the procedural volume of the hospital concerned exceeded nine resections were included in the HVH group. In this group more patients with more comorbidity were operated, and the transhiatal approach was used more often than the transthoracic approach. Significantly more adverse events occurred in the LVH group, with a mortality rate of $6.3 \%$ in the LVH group and $2.9 \%$ in the HVH group (Table 6). After exclusion of the patients who died in hospital, median hospital stay was 8 days shorter in the HVH group. Survival analysis did not show a difference in 2-year survival between the LVH and HVH group $(P=0.63)$.

\section{DISCUSSION}

In the last decade, many studies have been published that have addressed the volume-outcome relationship for 
TABLE 3 Cox multivariate model adjusted for the impact of covariates on the risk of dying (HR) for patients who underwent esophageal resection for cancer by period of surgery

\begin{tabular}{|c|c|c|}
\hline & HR & $95 \% \mathrm{CI}$ \\
\hline \multicolumn{3}{|l|}{ Univariate } \\
\hline 1990-1994 & 1.00 & \\
\hline 1995-1999 & 0.89 & $0.69-1.14$ \\
\hline 2000-2004 & 0.66 & $0.50-0.86$ \\
\hline \multicolumn{3}{|c|}{${\text { Adjusted for } \text { stage }^{\mathrm{a}} \text { and comorbidity }}^{\mathrm{a}}$} \\
\hline 1990-1994 & 1.00 & \\
\hline 1995-1999 & 0.82 & $0.61-1.11$ \\
\hline 2000-2004 & 0.57 & $0.42-0.77$ \\
\hline \multicolumn{3}{|c|}{$\begin{array}{l}\text { Adjusted for stage }{ }^{\mathrm{a}} \text {, comorbidity }{ }^{\mathrm{a}} \text {, and surgical } \\
\text { approach }^{\mathrm{a}}\end{array}$} \\
\hline 1990-1994 & 1.00 & \\
\hline 1995-1999 & 0.85 & $0.62-1.15$ \\
\hline 2000-2004 & 0.60 & $0.43-0.84$ \\
\hline \multicolumn{3}{|c|}{$\begin{array}{l}\text { Adjusted for } \text { stage }^{\mathrm{a}} \text {, comorbidity }{ }^{\mathrm{a}} \text {, surgical } \\
\text { approach }^{\mathrm{a}} \text {, and neoadjuvant treatment }\end{array}$} \\
\hline 1990-1994 & 1.00 & \\
\hline 1995-1999 & 0.85 & $0.63-1.16$ \\
\hline 2000-2004 & 0.61 & $0.44-0.86$ \\
\hline
\end{tabular}

complex surgical procedures. ${ }^{1,12}$ The results of these studies focus on the rather high difference in mortality rates between high- and low-volume providers for esophageal resections for cancer. ${ }^{7}$ As a consequence, these authors speculate that concentration of these high-risk surgical procedures in centers with adequate experience could avoid thousands of preventable deaths. ${ }^{5,13}$ However, the present study is the first that shows an actual improvement in outcome after the process of centralization of esophageal resections for cancer.

Chowdhury et al. reviewed 163 studies that looked at the volume-outcome relationship for complex surgical procedures. ${ }^{1}$ Seventy-three percent of these studies showed significant better outcomes in high-volume hospitals and for high-volume surgeons. However, most studies are registry-based and omit important case-mix adjustments from clinical data. Moreover, hospital mortality is often presented as the sole outcome measure, without presenting other dimensions of quality of care. Therefore, there is solid criticism on the methodological issues, which hampers centralization initiatives for complex surgical procedures, especially in The Netherlands. Despite the expected benefits of centralizing complex surgical procedures at high-volume providers, there are few studies that show an actual improvement in clinical outcome after centralization of a specific procedure. ${ }^{14}$ As a part of a broader initiative, the Leapfrog Group, a large coalition of
TABLE 4 Cox multivariate model adjusted for the impact of covariates on the risk of dying (HR) for patients who underwent esophageal resection by period of surgery (patients who died inhospital excluded)

\begin{tabular}{|c|c|c|}
\hline & HR & $95 \% \mathrm{CI}$ \\
\hline \multicolumn{3}{|l|}{ Univariate } \\
\hline 1990-1994 & 1.00 & \\
\hline 1995-1999 & 0.87 & $0.64-1.20$ \\
\hline 2000-2004 & 0.66 & $0.48-0.91$ \\
\hline \multicolumn{3}{|c|}{ Adjusted for stage ${ }^{a}$} \\
\hline 1990-1994 & 1.00 & \\
\hline 1995-1999 & 0.90 & $0.65-1.24$ \\
\hline 2000-2004 & 0.67 & $0.48-0.93$ \\
\hline \multicolumn{3}{|c|}{ Adjusted for stage ${ }^{\mathrm{a}}$, age, and gender } \\
\hline 1990-1994 & 1.00 & \\
\hline 1995-1999 & 0.88 & $0.64-1.22$ \\
\hline 2000-2004 & 0.67 & $0.48-0.93$ \\
\hline \multicolumn{3}{|c|}{ Adjusted for stage $^{\mathrm{a}}$, age, gender, and comorbidity ${ }^{\mathrm{a}}$} \\
\hline 1990-1994 & 1.00 & \\
\hline 1995-1999 & 0.88 & $0.64-1.22$ \\
\hline 2000-2004 & 0.67 & $0.48-0.93$ \\
\hline \multicolumn{3}{|c|}{$\begin{array}{l}\text { Adjusted for stage }{ }^{\mathrm{a}} \text {, age, gender, comorbidity }{ }^{\mathrm{a}} \text {, and } \\
\text { surgical approach }\end{array}$} \\
\hline 1990-1994 & 1.00 & \\
\hline 1995-1999 & 0.92 & $0.66-1.29$ \\
\hline 2000-2004 & 0.75 & $0.52-1.07$ \\
\hline
\end{tabular}

$H R$ hazard ratio, $C I$ confidence interval

a "Unknown" categories were excluded

private and public purchasers of health insurance in the USA, has been referring their patients to high-volume providers of esophagectomies since 2000. Although expectations about the beneficial effects of this intervention were high, no results have been published yet. ${ }^{5,13}$

Our study adds clinical proof to the effectiveness of concentrating complex surgical procedures: not only was hospital mortality reduced to a third of the original value, but also other outcome indicators, such as the number and severity of adverse events, showed improvement after centralization of esophagectomies in the CCCW region in The Netherlands. This was also reflected in a lower number of reinterventions and shorter length of stay. Remarkable is the significant improvement in survival that is already demonstrated after a limited concentration of esophageal resections (Fig. 2). In our opinion, overall survival, adjusted for differences in tumor stages, should be the most important performance indicator in surgical oncology, being even more valuable than operative mortality.

In an earlier article from our group we showed that case mix is an important determinant of outcome and should be part of every study comparing outcome between 
TABLE 5 Characteristics of patients who underwent esophageal resection by hospital volume in the 2000-2004 time period

LVHs low-volume hospitals $(<10$ resections/year), HVHs high-volume hospitals $(\geq 10$ resections/year), GE gastroesophageal

a "Unknown" category excluded

b Adenocarcinoma/Barrett's dysplasia versus squamous and others

c Distal esophagus/GE junction versus cervical/mid esophagus

d No neoadjuvant therapy versus others

e Abdomino-cervical versus others

${ }^{\mathrm{f}}$ Cervical anastomoses versus others

\begin{tabular}{|c|c|c|c|c|c|}
\hline \multirow[t]{2}{*}{ Characteristics } & \multicolumn{2}{|l|}{ LVHs } & \multicolumn{2}{|l|}{ HVHs } & \multirow[t]{2}{*}{$P$ value } \\
\hline & No. of patients & $\%$ & No. of patients & $\%$ & \\
\hline Age (years) & & & & & 0.24 \\
\hline Median & 64 & & 63 & & \\
\hline Range & $33-86$ & & $43-80$ & & \\
\hline Gender & & & & & 0.53 \\
\hline Male & 80 & 72.1 & 79 & 76.7 & \\
\hline Female & 31 & 27.9 & 24 & 23.3 & \\
\hline Comorbidity & & & & & $0.001^{\mathrm{a}, *}$ \\
\hline No & 56 & 50.5 & 27 & 26.2 & \\
\hline 1 organ system & 35 & 31.5 & 50 & 48.5 & \\
\hline 2 organ systems & 18 & 16.2 & 23 & 22.3 & \\
\hline$\geq 3$ organ systems & 1 & 0.9 & 3 & 2.9 & \\
\hline Unknown & 1 & 0.9 & - & - & \\
\hline Histology & & & & & $0.98^{\mathrm{a}, \mathrm{b}}$ \\
\hline Adenocarc. & 73 & 65.8 & 71 & 68.9 & \\
\hline Squamous & 27 & 24.3 & 25 & 24.3 & \\
\hline Barrett's dysplasia & 3 & 2.7 & 3 & 2.9 & \\
\hline Other & 2 & 1.8 & 3 & 2.9 & \\
\hline Unknown & 6 & 5.4 & 1 & 1.0 & \\
\hline Tumor localization & & & & & $0.61^{\mathrm{a}, \mathrm{c}}$ \\
\hline Cervical esoph. & 2 & 1.8 & 2 & 1.9 & \\
\hline Mid esoph. & 18 & 16.2 & 14 & 13.6 & \\
\hline Distal esoph./GE junction & 90 & 81.1 & 87 & 84.5 & \\
\hline Unknown & 1 & 0.9 & - & - & \\
\hline Stage (pTNM) & & & & & $0.90^{\mathrm{a}}$ \\
\hline 0 & 3 & 2.7 & 3 & 2.9 & \\
\hline I & 15 & 13.5 & 16 & 15.5 & \\
\hline II & 43 & 38.7 & 39 & 37.9 & \\
\hline III & 39 & 35.1 & 35 & 34.0 & \\
\hline IV & 6 & 5.4 & 9 & 8.7 & \\
\hline Unknown & 5 & 4.5 & 1 & 1.0 & \\
\hline Neoadjuvant treatment & & & & & $0.27^{\mathrm{a}, \mathrm{d}}$ \\
\hline No & 90 & 81.1 & 70 & 68.0 & \\
\hline Chemo \pm radiotherapy & 21 & 18.9 & 33 & 32.0 & \\
\hline Surgical approach & & & & & $<0.001^{\mathrm{a}, \mathrm{e}}$ \\
\hline Abdomino-cervical & 66 & 59.5 & 90 & 87.4 & \\
\hline Thoraco-abdominal & 10 & 9.0 & 1 & 1.0 & \\
\hline Abd-thor-cervical & 17 & 15.3 & 10 & 9.7 & \\
\hline Abdominal & 14 & 12.6 & 1 & 1.0 & \\
\hline Unknown & 4 & 3.6 & 1 & 1.0 & \\
\hline Anastomoses & & & & & $<0.001^{\mathrm{f}}$ \\
\hline Cervical & 86 & 77.5 & 101 & 98.1 & \\
\hline Thoracic & 12 & 10.8 & - & - & \\
\hline Abdominal & 13 & 11.7 & 2 & 1.9 & \\
\hline Total no. of patients & 111 & & 103 & & \\
\hline
\end{tabular}

providers. ${ }^{10}$ Therefore, we tried to study the effect of differences in case mix between the hospitals. The identification of more patients with multiple comorbid diseases and more patients with stage IV disease in the last time period (Table 1) supports our conclusion that outcome improved with centralization of esophageal resections. 
TABLE 6 Outcome after esophageal resections by hospital volume in the 2000 2004 time-period
LVHs low-volume hospitals $(<10$ resections/year), $H V H s$ high-volume hospitals $(\geq 10$ resections/year)

${ }^{a}$ Patients who died during hospital stay were not included

b "Unknown" category excluded

c R0 versus R1 plus R2

${ }^{\mathrm{d}}$ No reintervention versus others

\begin{tabular}{|c|c|c|c|c|c|}
\hline \multirow[t]{2}{*}{ Outcome } & \multicolumn{2}{|l|}{ LVHs } & \multicolumn{2}{|l|}{ HVHs } & \multirow[t]{2}{*}{$P$ value } \\
\hline & No. of patients & $\%$ & No. of patients & $\%$ & \\
\hline Margins & & & & & $0.35^{\mathrm{b}, \mathrm{c}}$ \\
\hline R0 & 77 & 69.4 & 79 & 76.7 & \\
\hline $\mathrm{R} 1$ & 19 & 17.1 & 20 & 19.4 & \\
\hline $\mathrm{R} 2$ & 10 & 9.0 & 2 & 1.9 & \\
\hline Unknown & 5 & 4.5 & 2 & 1.9 & \\
\hline \multicolumn{6}{|l|}{ Complications } \\
\hline No & 24 & 21.6 & 46 & 44.7 & $0.001^{\mathrm{b}}$ \\
\hline Yes & 86 & 77.5 & 57 & 55.3 & \\
\hline Unknown & 1 & 0.9 & - & - & \\
\hline Surgical complications & & & & & $0.05^{\mathrm{b}}$ \\
\hline No & 54 & 48.6 & 64 & 62.1 & \\
\hline Yes & 56 & 50.5 & 39 & 37.9 & \\
\hline Unknown & 1 & 0.9 & - & - & \\
\hline General complications & & & & & $0.001^{\mathrm{b}}$ \\
\hline No & 44 & 39.6 & 65 & 63.1 & \\
\hline Yes & 66 & 59.5 & 38 & 36.9 & \\
\hline Unknown & 1 & 0.9 & - & - & \\
\hline Reintervention & & & & & $0.39^{\mathrm{b}, \mathrm{d}}$ \\
\hline None & 82 & 73.9 & 81 & 78.6 & \\
\hline 1 & 19 & 17.1 & 13 & 12.6 & \\
\hline 2 & 7 & 6.3 & 5 & 4.9 & \\
\hline$\geq 3$ & 1 & 0.9 & 2 & 1.9 & \\
\hline Unknown & 2 & 1.8 & 2 & 1.9 & \\
\hline Hospital stay (days) ${ }^{\mathrm{a}}$ & & & & & $<0.001$ \\
\hline Median & 22 & & 14 & & \\
\hline Range & $(10-273)$ & & $(8-104)$ & & \\
\hline In-hospital mortality & & & & & 0.24 \\
\hline No & 104 & 93.7 & 100 & 97.1 & \\
\hline Yes & 7 & 6.3 & 3 & 2.9 & \\
\hline Total no. of patients & 111 & & 103 & & \\
\hline
\end{tabular}

However, our study has several limitations. First, the accuracy of the registry database should be confirmed. This was done by comparing the results with the data of the independently retrieved information in the cancer registry of the CCCW. Only 3\% of the patients operated on for esophageal cancer in our region were missing from our prospective database. The treatment and outcome characteristics of this small group of patients did not differ significantly from those of the original group. An earlier report on a detailed medical audit confirms the accuracy of clinical outcomes databases on major fields such as operative mortality, major complications, and significant factors in risk stratification. ${ }^{15}$

Secondly, our dataset is still limited, though more (co)variables were included than in most volume-outcome studies. In contrast to the available data on case-mix variations, no information on structural changes in perioperative care was available. To our knowledge no important improvements in the treatment of esophageal cancer are known from the literature, nor within the region of the CCCW. Nevertheless, progress in anesthesiological techniques and postoperative care within the study period could have interfered with our findings. In addition, limited data were available on the survival of patients in the later time period (2-year survival). This could be insufficient to evaluate differences in disease control obtained by transthoracic and transhiatal procedures. Recently, the 5-year survival data of the Dutch randomized controlled trial comparing these surgical approaches were published. ${ }^{16}$ No survival benefit was shown for either approach. Nevertheless, after introducing surgical approach in our multivariate analyses (Table 4), the statistical difference in survival between the time periods was lost, suggesting an important role for the choice of operative approach. In our opinion, 
the choice for a transhiatal or transthoracic procedure is made in a decision-making process in which careful interpretation of diagnostic images and surgical experience are combined. The increase in hospital volumes, as a result of the concentration of esophagectomies in our study, might have led to better surgical decision-making, especially in the choice of operative approaches.

The beneficial effects of the centralization process conducted in the last time period are further supported by the comparison of outcome between LVHs and the hospitals that acquired the status of $\mathrm{HVH}(\geq 10$ resections/year) in the last time period (Table 6). Although differences in operative mortality are not significant, they strongly suggest that the most important improvement in outcome is made in the HVHs, which now parallel the outcome in the nearest high-volume referral center (data not shown). Differences in case mix, especially comorbidities, are also in favor of the HVHs (Table 5). Continuation of the centralization process and the outcome registration in our region will elucidate the mechanisms behind these improvements in patient outcome. From 1st January 2005 esophagus resections in the region of the CCCW are concentrated in three hospitals with mean annual volume of more than 15 esophagus resections.

Finally, the feedback we gave to individual surgeons and hospital organizations on their performance (mirror information) could in itself have influenced practice patterns and dedication of the professionals. When outcomes data are used for internal peer review within institutions, changes in the process of care can be initiated by surgeons or hospitals themselves. A good example is the Veterans Affairs National Surgical Quality Improvement Program (NSQIP) in which feedback to providers and managers led to a decrease in the relative risk for postoperative mortality of $27 \%$ and a $45 \%$ decrease in postoperative morbidity. ${ }^{17}$ However, this program was more detailed, consisting of outcome-based annual reports, periodic assessment of performance, self-assessment tools, structured site visits, and dissemination of best practices. Nevertheless, the observed improvements in outcome in our study could be not only a result of the concentration of services but also of the introduced feedback on surgical performance. This could explain the improved outcome that was also demonstrated in the LVHs, being of a lesser magnitude than the improvements in HVHs (Table 6).

Some authors believe that procedural volume, as a proxy for quality, is preferable above direct outcomes measurement. ${ }^{18,19}$ The availability and easy access of these data and the avoidance of the statistical problem of small sample size are mentioned as important advantages. ${ }^{20}$ However, in a study from our own country, van Heek et al. showed that, despite a 10-year-long "evidence-based" plea for centralization of pancreatic surgery, no reduction of mortality or change in referral pattern was seen in The Netherlands. ${ }^{21}$ The problem is that provider volume as a quality measure only holds true on average, and is a poor predictor of quality in individual hospitals or surgeons. ${ }^{22,23}$

In our opinion, continuous monitoring of clinical outcomes not only has the ability to assess quality of care but can actually improve surgical performance. A number of methods for surgical monitoring, which take into account different levels of prior risk, have been described in the literature. $^{24,25}$ A routinely conducted medical audit, providing hospitals and surgeons with individualized and pooled outcome information, can be a stimulus for the introduction of a range of improvements in hospital and surgical care. ${ }^{26-28}$ In addition, a national or regional approach, such as the example for esophageal cancer surgery in our study, clarifies important differences in quality of care. In a peer-review environment or when reliable, hospital-specific outcome information is made available to the public, actual changes in referral patterns can be made (outcome-based referral).

ACKNOWLEDGEMENT The authors thank the participating surgeons for their cooperative and selfless attitude in improving the quality of care for esophageal cancer patients in the region of the Comprehensive Cancer Center West.

Open Access This article is distributed under the terms of the Creative Commons Attribution Noncommercial License which permits any noncommercial use, distribution, and reproduction in any medium, provided the original author(s) and source are credited.

\section{REFERENCES}

1. Chowdhury MM, Dagash H, Pierro A. A systematic review of the impact of volume of surgery and specialization on patient outcome. Br J Surg. 2007;94:145-61.

2. Urbach DR, Austin PC. Conventional models overestimate the statistical significance of volume-outcome associations, compared with multilevel models. J Clin Epidemiol. 2005;58:391-400.

3. Metzger R, Bollschweiler E, Vallbohmer D, Maish M, DeMeester TR, Holscher AH. High volume centers for esophagectomy: what is the number needed to achieve low postoperative mortality? Dis Esophagus. 2004;17:310-4.

4. Holscher AH, Metzger R, Brabender J, Vallbohmer D, Bollschweiler E. High-volume centers-effect of case load on outcome in cancer surgery. Onkologie. 2004;27:412-6.

5. Birkmeyer JD, Finlayson EV, Birkmeyer CM. Volume standards for high-risk surgical procedures: potential benefits of the Leapfrog initiative. Surgery. 2001;130:415-22.

6. Gandjour A, Bannenberg A, Lauterbach KW. Threshold volumes associated with higher survival in health care: a systematic review. Med Care. 2003;41:1129-41.

7. Birkmeyer JD, Siewers AE, Finlayson EV, Stukel TA, Lucas FL, Batista I, et al. Hospital volume and surgical mortality in the United States. N Engl J Med. 2002;346:1128-37.

8. Killeen SD, O'Sullivan MJ, Coffey JC, Kirwan WO, Redmond HP. Provider volume and outcomes for oncological procedures. Br J Surg. 2005;92:389-402. 
9. van Lanschot JJ, Hulscher JB, Buskens CJ, Tilanus HW, ten Kate FJ, Obertop H. Hospital volume and hospital mortality for esophagectomy. Cancer. 2001;91:1574-8.

10. Wouters MW, Wijnhoven BP, Karim-Kos HE, Blaauwgeers HG, Stassen LP, Steup WH, et al. High-volume versus low-volume for esophageal resections for cancer: the essential role of case-mix adjustments based on clinical data. Ann Surg Oncol. 2008;15 (1):80-7.

11. Cunningham D, Allum WH, Stenning SP, et al. Perioperative chemotherapy versus surgery alone for resectable gastroesophageal cancer. N Engl J Med. 2006;355:11-20.

12. Halm EA, Lee $C$, Chassin MR. Is volume related to outcome in health care? A systematic review and methodologic critique of the literature. Ann Intern Med. 2002;137:511-20.

13. Dudley RA, Johansen KL, Brand R, Rennie DJ, Milstein A. Selective referral to high-volume hospitals: estimating potentially avoidable deaths. JAMA. 2000;283:1159-66.

14. O'Connor GT, Plume SK, Olmstead EM, et al. A regional intervention to improve the hospital mortality associated with coronary artery bypass graft surgery. The Northern New England Cardiovascular Disease Study Group. JAMA. 1996;275:841-6.

15. Herbert MA, Prince SL, Williams JL, Magee MJ, Mack MJ. Are unaudited records from an outcomes registry database accurate? Ann Thorac Surg. 2004;77:1960-4.

16. Omloo JM, Lagarde SM, Hulscher JB, et al. Extended transthoracic resection compared with limited transhiatal resection for adenocarcinoma of the mid/distal esophagus: five-year survival of a randomized clinical trial. Ann Surg. 2007;246:992-1000.

17. Khuri SF, Daley J, Henderson WG. The comparative assessment and improvement of quality of surgical care in the Department of Veterans Affairs. Arch Surg. 2002;137:20-7.

18. Dimick JB, Birkmeyer JD, Upchurch GR, Jr. Measuring surgical quality: what's the role of provider volume? World J Surg. 2005; 29:1217-21.
19. Birkmeyer JD, Dimick JB, Staiger DO. Operative mortality and procedure volume as predictors of subsequent hospital performance. Ann Surg. 2006;243:411-7.

20. Dimick JB, Welch HG, Birkmeyer JD. Surgical mortality as an indicator of hospital quality: the problem with small sample size. JAMA. 2004;292:847-51.

21. van Heek NT, Kuhlmann KF, Scholten RJ, et al. Hospital volume and mortality after pancreatic resection: a systematic review and an evaluation of intervention in the Netherlands. Ann Surg. 2005; 242:781-8, discussion.

22. Rathore SS, Epstein AJ, Volpp KG, Krumholz HM. Hospital coronary artery bypass graft surgery volume and patient mortality, 1998-2000. Ann Surg. 2004;239:110-7.

23. Birkmeyer JD, Dimick JB, Birkmeyer NJ. Measuring the quality of surgical care: structure, process, or outcomes? J Am Coll Surg. 2004;198:626-32.

24. Lovegrove J, Valencia O, Treasure T, Sherlaw-Johnson C, Gallivan S. Monitoring the results of cardiac surgery by variable lifeadjusted display. Lancet. 1997;350:1128-30.

25. Steiner SH, Cook RJ, Farewell VT, Treasure T. Monitoring surgical performance using risk-adjusted cumulative sum charts. Biostatistics. 2000;1:441-52.

26. Jarman B, Bottle A, Aylin P, Browne M. Monitoring changes in hospital standardised mortality ratios. BMJ. 2005;330:329.

27. Wright J, Dugdale B, Hammond I et al. Learning from death: a hospital mortality reduction programme. J R Soc Med. 2006;99: 303-8.

28. Reilly J, Mitchell A, Blue J, Thomson W. Breast cancer audit: adapting national audit frameworks for local review of clinical practice. Health Bull (Edinb). 2001;59:60-2. 